\title{
Cancer stem cell-related marker expression in lung adenocarcinoma and relevance of histologic subtypes based on IASLC/ATS/ERS classification
}

This article was published in the following Dove Press journal:

OncoTargets and Therapy

7 November 2013

Number of times this article has been viewed

\author{
Yoshihisa Shimada' \\ Hisashi Saji ${ }^{3}$ \\ Masaharu Nomura ${ }^{1,2}$ \\ Jun Matsubayashi \\ Koichi Yoshida' \\ Masatoshi Kakihana' \\ Naohiro Kajiwara' \\ Tatsuo Ohira' \\ Norihiko Ikeda' \\ 'Department of Surgery I, \\ 2Department of Anatomic Pathology, \\ Tokyo Medical University Hospital, \\ Tokyo, Japan; ${ }^{3}$ Department of Chest \\ Surgery, St Marianna University \\ School of Medicine, Kawasaki, Japan
}

Background: The cancer stem cell (CSC) theory has been proposed to explain tumor heterogeneity and the carcinogenesis of solid tumors. The aim of this study was to clarify the clinical role of CSC-related markers in patients with lung adenocarcinoma and to determine whether each CSC-related marker expression correlates with the histologic subtyping proposed by the International Association for the Study of Lung Cancer (IASLC), the American Thoracic Society (ATS), and the European Respiratory Society (ERS) classifications.

Methods: We reviewed data for all 103 patients in whom complete resection of adenocarcinoma had been performed. Expression of CSC-related markers, ie, aldehyde dehydrogenase 1A1 (ALDH1A1), aldo-keto reductase 1C family member 1 (AK1C1), and 1C family member 3 (AK1C3), was examined using immunostaining on whole-mount tissue slides, and the tumors were reclassified according to the IASLC/ATS/ERS classification.

Results: ALDH1A1 expression was observed in $66.0 \%$ of tumors, AK1C1 in $62.7 \%$, and AK1C3 in $86.1 \%$. Immunoreactivities with the frequency of mean expression of ALDH1A1 in papillary predominant adenocarcinoma were significantly higher than those of solid predominant adenocarcinoma $(P<0.05)$. Papillary predominant adenocarcinoma had significantly lower expression of $\mathrm{AK} 1 \mathrm{C} 1$ when compared with noninvasive or solid predominant adenocarcinomas $(P<0.05)$. On multivariate analysis, larger tumor size (hazards ratio $1.899, P=0.044)$, lymph node metastasis (hazards ratio 2.702, $P=0.005$ ), and low expression of ALDH1A1 (hazards ratio $3.218, P<0.001$ ) were shown to be independently associated with an unfavorable prognosis.

Conclusion: Immunohistochemistry of ALDH1A1 expression is strongly associated with prognosis. Expression of each CSC-related marker varies according to subtype, suggesting that a comprehensive histologic subtyping approach in the IASLC/ATS/ERS classification provides new molecular biology insights into the genesis of lung adenocarcinoma according to CSC theory.

Keywords: cancer stem cell marker, adenocarcinoma, ALDH1A1, AK1C1, AK1C3, prognosis

\section{Introduction}

Lung cancer is the most lethal of all cancers, and adenocarcinoma (ADC) is the most common histopathologic type of lung cancer worldwide. ${ }^{1}$ Major advances in ADC management have resulted from the understanding of molecular biology, development of molecular targeting agents, and identification of biomarkers for targeted treatment. However, there exists a widely divergent clinical, radiologic, molecular and pathologic spectrum in lung ADC. In this context, the International Association for the Study of Lung Cancer (IASLC), the American Thoracic Society (ATS), and the European Respiratory Society (ERS) have proposed a new subclassification of lung ADCs that relies on the predominant structural morphology. ${ }^{2}$ Histologic subtyping according to
Correspondence: Yoshihisa Shimada Department of Surgery I, Tokyo Medical University, 6-7-I Nishishinjuku, Shinjuku-ku, Tokyo, 160-0023, Japan Tel $+8 \mathrm{I} 0333426 \mathrm{III}$

Fax +81 0333426203

Email zenkyu@za3.so-net.ne.jp 
the IASLC/ATS/ERS classification has been reported to have a strong relationship with prognosis in several studies. ${ }^{3-7}$

Cancer stem cell (CSC) theory has been proposed to explain tumor heterogeneity and the carcinogenesis of solid tumors, including lung cancer. ${ }^{8} \mathrm{CSCs}$, a very small population of specialized cells, have potential for self-renewal and extensively proliferative characteristics that sustain tumor formation. ${ }^{8,9}$ Various molecules are being investigated as putative markers of CSCs. In this study, we focused on aldehyde dehydrogenase 1A1 (ALDH1A1), aldo-keto reductase $1 \mathrm{C}$ family member 1 (AK1C1), and $1 \mathrm{C}$ family member 3 (AK1C3), which have been previously identified as labeling CSCs in breast, colon, prostate, and lung cancer. ${ }^{10-15}$ In particular, ALDH1 has already been evaluated as an effective prognostic marker in lung cancer. ${ }^{12,15,16}$

In the current study, we attempted to determine whether expression of each CSC-related marker is correlated with the IASLC/ATS/ERS classification, and whether expression of CSC-related markers has any bearing on overall survival.

\section{Materials and methods}

\section{Patients}

The subjects recruited for this study consisted of 103 patients with lung ADC who underwent complete surgical resection at Tokyo Medical University Hospital between December 1999 and January 2002. All of these patients underwent complete lobar resection and systematic mediastinal lymph node dissection. We excluded patients who had undergone preoperative chemotherapy or radiotherapy. Diagnoses were made according to the criteria of the current World Health Organization classification for lung cancer and the IASLC/ ATS/ERS international multidisciplinary classification of lung ADC. ${ }^{2}$ The 7 th edition International Union Against Cancer/American Joint Committee on Cancer TNM classification was applied to all ADCs. ${ }^{17}$ Data collection and analyses were approved, and the need to obtain written informed consent from each patient was waived by the Tokyo Medical University institutional review board.

Clinical characteristics were retrieved from the clinical records available. The following clinicopathologic factors were assessed retrospectively in relation to immunohistochemical analysis: age, gender, smoking history, pathologic staging, tumor size, pathologic nodal involvement, grade of differentiation, vascular invasion, and pleural invasion.

\section{Histopathology}

After the specimens were fixed with formalin and embedded in paraffin, serial $4 \mu \mathrm{m}$ sections were stained with hematoxylin and eosin and by the Alcian Blue-periodic acid-Schiff method to visualize cytoplasmic mucin and by the Elastica van Gieson method to visualize elastic fibers. All slides were evaluated by three of the authors (YS, MN, JM) together using a multiheaded microscope and discussed until consensus was achieved.

All tumor areas were evaluated on the slides. If several tumor foci were present, all foci were included in the analysis. Evaluation was done according to the criteria of the IASLC/ATS/ERS classification, recording the percentage of each histologic component in 5\% increments: adenocarcinoma in situ (Figure 1A), minimally invasive adenocarcinoma (Figure 1B), lepidic and acinar (Figure 1C), solid (Figure 1D), papillary, micropapillary (Figure 1E), and mucinous predominant (Figure 1F). The predominant pattern was defined as the pattern with the largest area percentage.

\section{Immunohistochemistry}

Expression of three CSC-related proteins was tested with the following commercially available antibodies according to the respective manufacturer's protocols: monoclonal rabbit anti-ALDH1A1 antibody (Abcom Japan, Tokyo, Japan), polyclonal anti-AK1C1 antibody (GeneTex, Irvine, CA, USA), and monoclonal anti AK1C3 antibody (Sigma Japan, Tokyo, Japan). Sections were briefly incubated with xylene, rehydrated with graded ethanol solutions, and incubated with methyl alcohol containing 3\% hydrogen peroxide to remove endogenous peroxidase activity. After washing thoroughly with phosphate-buffered saline, sections were incubated with adequately diluted primary antibodies and then with Histofine ${ }^{\circledR}$ simple stain (Nichirei Bioscience, Tokyo, Japan), and finally visualized with products of the peroxidase and diaminobenzidine reaction.

Antibody binding was microscopically recognizable as brown cytoplasmic staining. We categorized immunoreactivity by the percentage of the immunopositive area. In tumor cells of interest, when more than $5 \%$ of the staining extensiveness showed an unequivocally strong reaction with an antibody, the tumor was classified as positive.

\section{Statistical analysis}

Overall survival was measured from the date of surgery to the date of death from any cause or the date on which the patient was last known to be alive. Survival curves were plotted according to the Kaplan-Meier method and compared using the log-rank test. Categoric comparisons were performed using the Pearson chi-squared test. Multivariate analysis was performed using the Cox proportional hazards model. A 

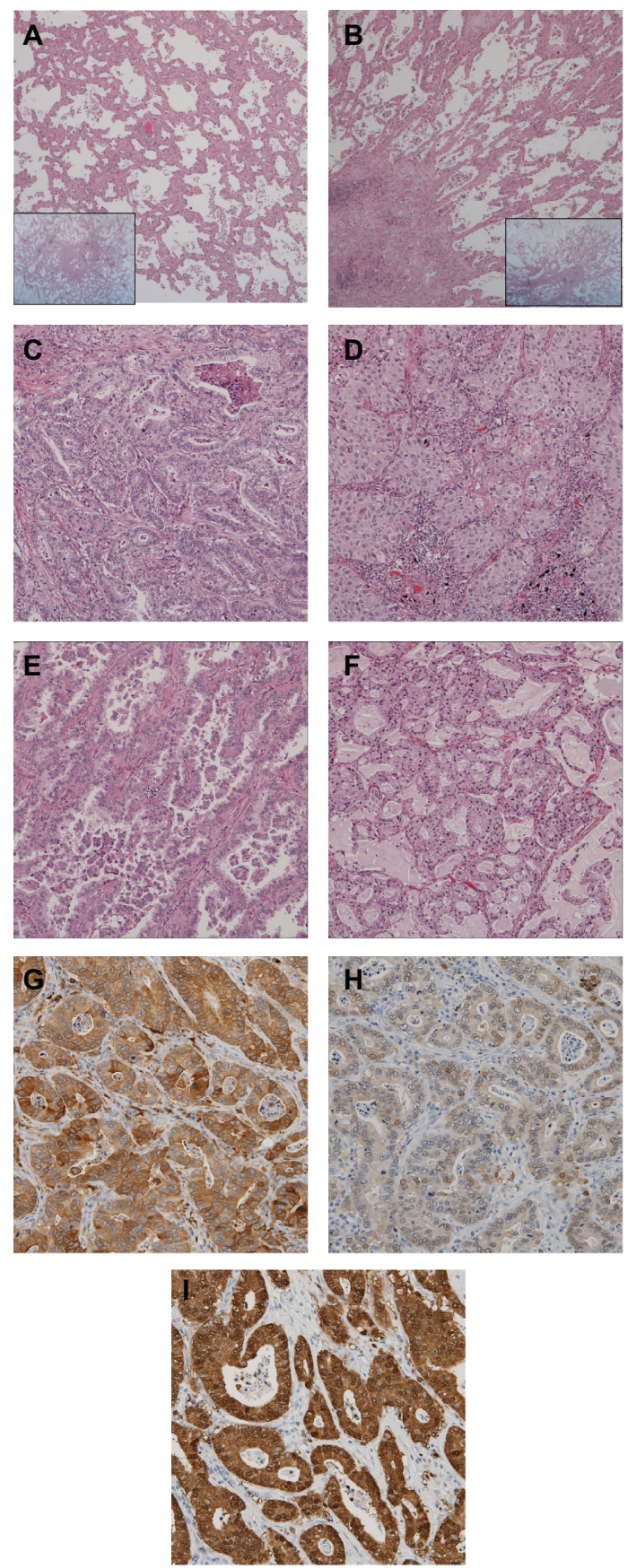

Figure I Images of predominant growth patterns and immunohistochemical staining of ALDHI, AKICI, and AKIC3. (A) Adenocarcinoma in situ, (B) minimally invasive adenocarcinoma, (C) acinar, (D) solid, (E) micropapillary, and (F) mucinous predominant adenocarcinoma. Also shown are immunohistochemical staining images for (G) ALDHIAI, (H) AKICI, and (I) AKIC3. These slides correspond to the acinar predominant adenocarcinoma shown in Figure IC.

Abbreviations: ALDHIAI, aldehyde dehydrogenase $I A I ; A K I C I$, aldo-keto reductase IC family member I; AKIC3, aldo-keto reductase IC family member 3 .

one-way analysis of variance, with the Tukey-Kramer multiple comparison post hoc test, was used to allow for unequal sample sizes and determine whether there was a significant difference between the mean immunohistochemical extensiveness according to the predominant histologic pattern of
ADC. A $P$-value of less than 0.05 was considered to indicate a statistically significant difference. The Stat-view 5.0 software package was used to perform the statistical analysis (SAS Institute Inc., Cary, NC, USA).

\section{Results}

\section{Predominant growth pattern and ALDHIAI,AKICI, and $A K I C 3$ expression}

All resected specimens were reclassified according to the IASLC/ATS/ERS classification. Representative results are shown in Figure 1. Reclassification of the 103 specimens resulted in three adenocarcinoma in situ $(2.9 \%$, Figure $1 \mathrm{~A})$, six minimally invasive adenocarcinoma (5.8\%, Figure 1B), and 94 invasive ADCs (91.3\%). Invasive ADCs were further divided into: lepidic predominant, eight (7.8\%); papillary predominant, 39 (37.9\%); acinar predominant, ten $(9.7 \%$, Figure $1 \mathrm{C})$; solid predominant, 27 (26.2\%, Figure 1D); and micropapillary predominant, five (4.9\%, Figure 1E). Specific ADC subtypes included four invasive mucinous ADCs (3.9\%, Figure 1F) and one enteric ADC (1.0\%). Representative examples of immunohistochemical stains for ALDH1A1, AK1C1, and AK1C3 are shown in Figure 1G-I, respectively. This corresponds to the acinar predominant ADC shown in Figure 1C. These CSC-related markers were expressed mainly in the cytoplasm and membrane of the tumor cells. Tumor cells in 68 (66.0\%) of the 103 specimens were positive for ALDH1A1, tumor cells in $64(62.7 \%)$ were positive for $\mathrm{AK} 1 \mathrm{C} 1$, and tumor cells in 87 (86.1\%) were positive for AK1C3.

\section{Correlation between CSC-related marker expression and predominant ADC subtypes}

We investigated the correlation between expression of ALDH1A1, AK1C1, and AK1C3 and each predominant subtype. Figure 2 presents the immunohistochemical extensiveness results for adenocarcinoma in situ-minimally invasive ADC (noninvasive ADC), lepidic, acinar, solid, papillary, micropapillary, and mucinous ADC. Immunoreactivities with the percentage of immunopositive areas show that the mean expression of ALDH1A1 in papillary predominant ADCs was significantly higher than that in solid predominant ADCs (Figure 2A, $P<0.05$ ). On the other hand, Figure 2B shows that papillary predominant ADCs had significantly lower expression of AK1C1 compared with noninvasive or solid predominant ADCs $(P<0.05)$. No significant 


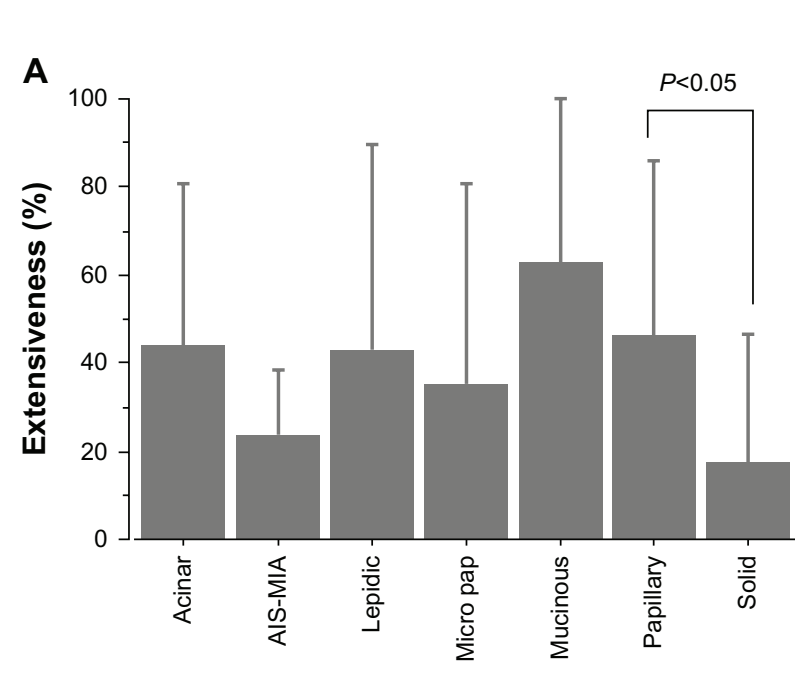

Histological subtype

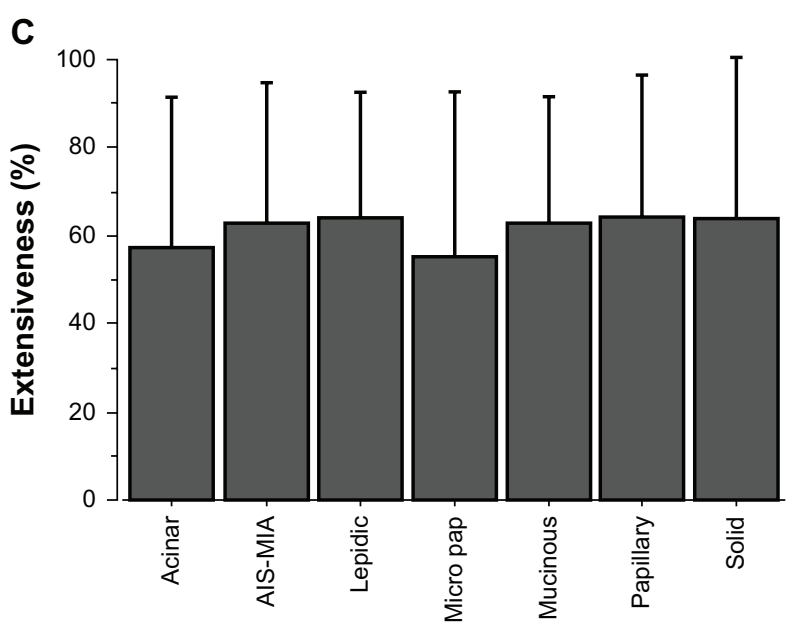

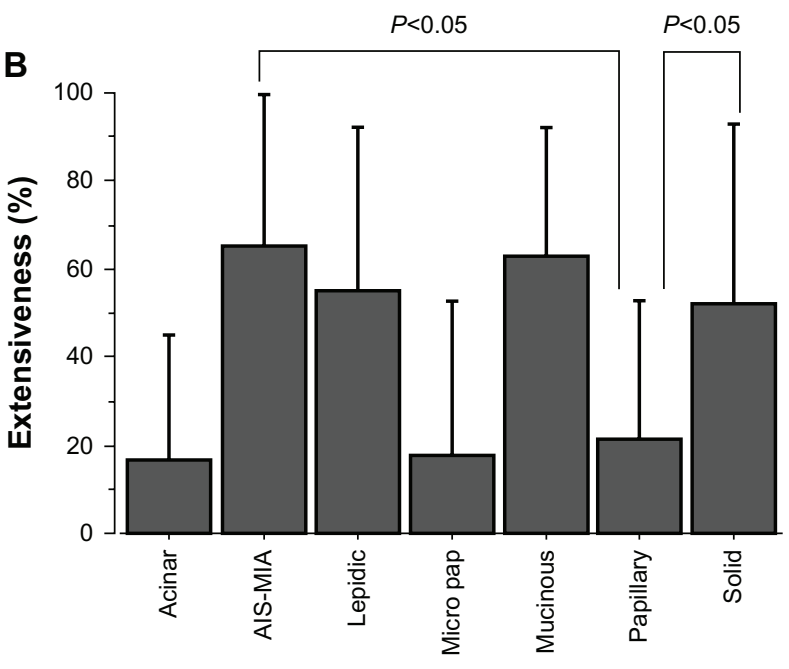

Histological subtype

Histological subtype

Figure 2 Cancer stem cell-related marker expression in each histologic subtype of lung adenocarcinoma. An overview of the correlation between ALDHIAI, AKICI, and AKIC3 expression and predominant subtypes is provided. The bars reflect the mean \pm standard error of the mean for extensiveness of the immunopositive area for each of the growth patterns. (A) Mean expression of ALDHIAI in papillary predominant adenocarcinomas is significantly higher than that in solid predominant adenocarcinomas $(P<0.05)$. (B) Papillary predominant adenocarcinomas had significantly lower expression of AKICl compared with noninvasive or solid predominant adenocarcinomas $(P<0.05)$. (C) No significant difference in AKIC3 expression was found for any predominant subtype.

Abbreviations: AIS, adenocarcinoma in situ; MIA, minimally invasive adenocarcinoma; ALDHIAI, aldehyde dehydrogenase IAI; AKICI, aldo-keto reductase IC family member I; AKIC3, aldo-keto reductase IC family member 3 .

difference in $\mathrm{AK} 1 \mathrm{C} 3$ expression was found between any of the predominant subtypes (Figure 2C).

\section{Patient characteristics \\ and survival analyses}

The median follow-up for survivors was 8.9 years. Table 1 shows the 5 -year overall survival proportions according to clinicopathologic characteristics in 103 patients with lung ADC. On univariate analysis, pathologic stage, tumor size, lymph node involvement, histologic vascular invasion, pleural invasion, and ALDH1 A1 immunoreactivity status were found to be significantly associated with survival outcome. The 5 -year overall survival proportions of patients with ALDH1A1-positive status and ALDH1A1negative status were $77.9 \%$ and $62.2 \%$, respectively. Patients with an ALDH1A1-positive status had longer overall survival than those with an ALDH1A1-negative status ( $P=0.002$, Figure 3 ), whereas staining with AK1C1 and AK1C3 had no prognostic significance $(P=0.249$ and $P=0.113$, respectively). A multivariate Cox proportional hazards model demonstrated that larger tumor size (hazards ratio $1.899, P=0.044$ ), lymph node metastasis (hazards ratio 2.702, $P=0.005$ ), and low expression of ALDH1A1 immunoreactivity (hazards ratio $3.218, P<0.001$ ) were independently associated with unfavorable overall survival (Table 2). 
Table I Patient characteristics and univariate analysis of overall survival

\begin{tabular}{|c|c|c|c|}
\hline Variable & $\begin{array}{l}\text { Cases, } \\
\text { n (\%) }\end{array}$ & $\begin{array}{l}5 \text {-year } \\
\text { OS rate }\end{array}$ & $P$-value \\
\hline Overall & 103 & $72.6 \%$ & \\
\hline \multicolumn{4}{|l|}{ Age (years, median 65) } \\
\hline$<65$ & $50(49)$ & $73.6 \%$ & \\
\hline$\geq 65$ & $53(5 \mathrm{I})$ & $71.7 \%$ & 0.416 \\
\hline \multicolumn{4}{|l|}{ Gender } \\
\hline Male & $57(55)$ & $68.0 \%$ & \\
\hline Female & $46(45)$ & $78.3 \%$ & 0.226 \\
\hline \multicolumn{4}{|l|}{ Smoking status } \\
\hline Smoker & $59(57)$ & $67.8 \%$ & \\
\hline Never smoker & $44(43)$ & $79.2 \%$ & 0.458 \\
\hline \multicolumn{4}{|l|}{ p Stage } \\
\hline 1 & $78(76)$ & $83.2 \%$ & \\
\hline II & $12(12)$ & $66.7 \%$ & (Stage I \\
\hline III & $11(11)$ & $27.3 \%$ & versus II-IV) \\
\hline IV & $2(2)$ & $50.0 \%$ & $<0.001$ \\
\hline \multicolumn{4}{|l|}{ Tumor size } \\
\hline$\leq 3.0 \mathrm{~cm}$ & $61(59)$ & $80.0 \%$ & \\
\hline$>3.0 \mathrm{~cm}$ & $42(4 I)$ & $61.9 \%$ & 0.006 \\
\hline \multicolumn{4}{|l|}{ Lymph node metastasis } \\
\hline Absent & $82(80)$ & $81.5 \%$ & \\
\hline Present & $21(20)$ & $38.1 \%$ & $<0.001$ \\
\hline \multicolumn{4}{|l|}{ Differentiation } \\
\hline Well or moderate & $72(70)$ & $76.2 \%$ & \\
\hline Poor & $31(30)$ & $61.3 \%$ & 0.304 \\
\hline \multicolumn{4}{|c|}{ IASLC/ATS/ERS classification } \\
\hline AIS & $3(3)$ & $100 \%$ & \\
\hline MIA & $6(6)$ & $100 \%$ & \\
\hline Lepidic & $8(8)$ & $87.5 \%$ & \\
\hline Papillary & $39(38)$ & $64.1 \%$ & \\
\hline Acinar & $10(10)$ & $100 \%$ & \\
\hline Micropapillary & $5(5)$ & $40.0 \%$ & \\
\hline Solid & $27(26)$ & $66.7 \%$ & \\
\hline Mucinous & $4(4)$ & $100 \%$ & \\
\hline Other (enteric) & $\mathrm{I}(\mathrm{I})$ & $100 \%$ & \\
\hline \multicolumn{4}{|l|}{ Vascular invasion } \\
\hline Absent & $43(42)$ & $81.1 \%$ & \\
\hline Present & $56(58)$ & $64.3 \%$ & 0.001 \\
\hline \multicolumn{4}{|l|}{ Pleural invasion } \\
\hline Absent & $82(80)$ & $79.3 \%$ & \\
\hline Present & $21(20)$ & $45.7 \%$ & 0.005 \\
\hline \multicolumn{4}{|l|}{ Adjuvant chemotherapy } \\
\hline With & $40(39)$ & $75.0 \%$ & \\
\hline Without & $63(61)$ & $71.1 \%$ & 0.337 \\
\hline \multicolumn{4}{|l|}{ ALDHIAI expression } \\
\hline$<5 \%$ positive cells & $35(34)$ & $62.2 \%$ & \\
\hline$\geq 5 \%$ positive cells & $68(66)$ & $77.9 \%$ & 0.002 \\
\hline \multicolumn{4}{|l|}{$\mathrm{AKICI}$ expression } \\
\hline$<5 \%$ positive cells & $38(37)$ & $71.1 \%$ & \\
\hline$\geq 5 \%$ positive cells & $64(63)$ & $74.7 \%$ & 0.249 \\
\hline \multicolumn{4}{|l|}{ AKIC3 expression } \\
\hline$<5 \%$ positive cells & $14(14)$ & $61.9 \%$ & \\
\hline$\geq 5 \%$ positive cells & $87(86)$ & $74.7 \%$ & 0.113 \\
\hline
\end{tabular}

Abbreviations: AIS, adenocarcinoma in situ; MIA, minimally invasive adenocarcinoma; OS, overall survival; IASLC, International Association for the Study of Lung Cancer; ATS, American Thoracic Society; ERS, European Respiratory Society; ALDHIAI, aldehyde dehydrogenase IAI; AKICI, aldo-keto reductase IC family member I; AKIC3, aldo-keto reductase IC family member 3 .

\section{Correlation between clinicopathologic features and ALDHIAI expression}

ALDH1A1 expression status was the most powerful prognostic indicator in this cohort. Therefore, we examined correlations between ALDH1A1-positive cases and clinicopathologic features (Table 3). The ALDH1A1-positive cases were significantly associated with less poorly differentiated $\operatorname{ADC}(P=0.013)$. No other clinicopathologic factors were correlated with these cases.

\section{Discussion}

We set out to determine whether ALDH1A1 immunoreactivity status was the most powerful independent prognostic factor for overall survival in lung ADC, and expression of each CSC-related marker varied in histologic subtype according to the IASLC/ATS/ERS classification. To the best of our knowledge, the association between CSC-related marker expression and the IASLC/ATS/ERS classification has not been previously investigated in patients for all stages of lung ADC.

The three markers examined in this study have been previously reported as candidate CSC-related markers in different types of tumors. ALDH1 is a detoxifying enzyme responsible for oxidation of intracellular aldehydes. The ALDH isoform, ALDH1 A1, has been shown to play a role in drug resistance, and its activity has been used to identify stem-like subsets in human hematopoietic cancers and other solid tumors. ${ }^{18-25}$ Previously published studies reported that overexpression of ALDH1A1 correlated with poor prognosis in lung cancer. ${ }^{12,15}$ Theoretically, a high proportion of CSCs in the tumor should be associated with an unfavorable prognosis. However, our results show that increased expression of ALDH1A1 correlated with more favorable overall survival, so are very much in conflict with the above mentioned literature. One of the reasons for this discrepancy may lie in the methodologic differences or different cutoff values used for distinguishing between positive and negative CSC-related marker expression. Our method was based on evaluating whole-mount tissue slides and $66 \%$ of tumor specimens were ALDH1A1positive, whereas the results of the previous studies based on tissue microarrays showed only $29 \%-45 \%$ of tumor samples to be positive with a mixture of ADCs and other histology. ${ }^{12,15}$ Although the current study population was too small to draw any statistically definite conclusions, the methodology of using tissue microarray may prevent detailed observation and increase the rate of false-negative results. Kahlert et al reported that low immunohistochemical expression of ALDH1 in pancreatic cancer was associated with 


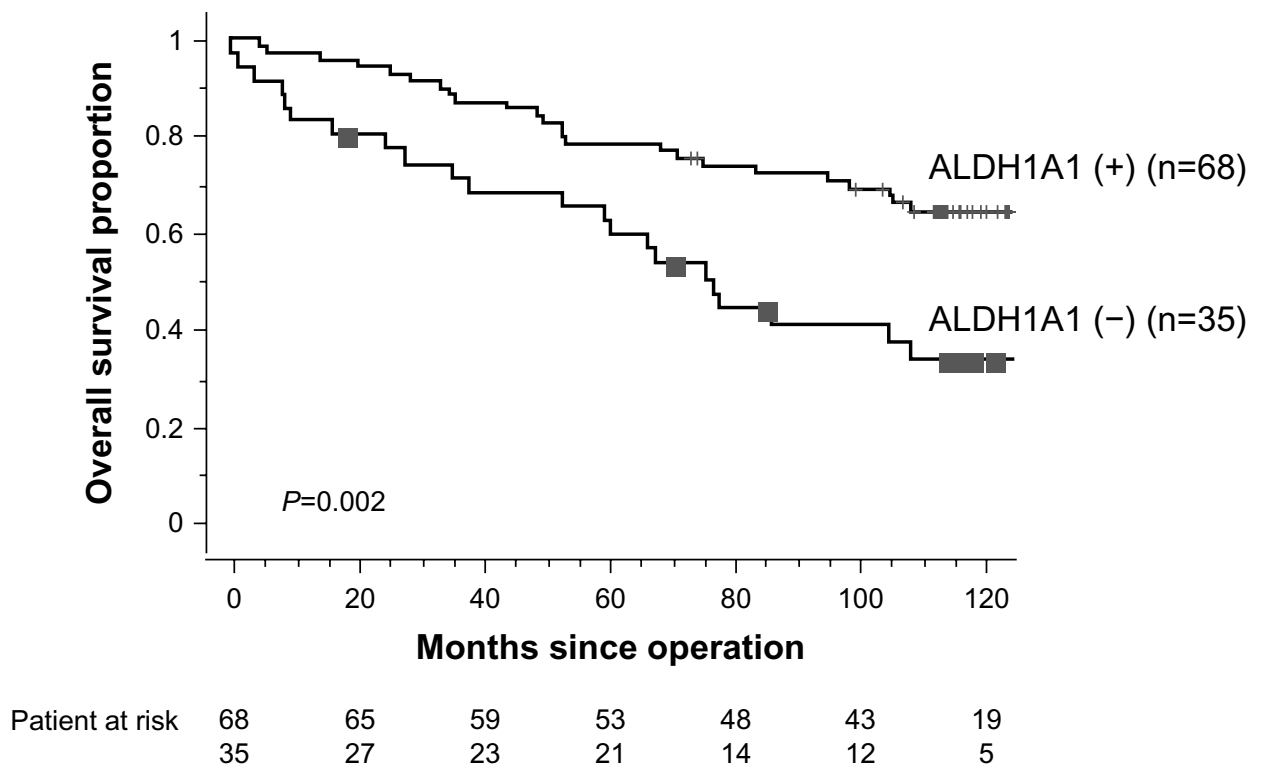

Figure 3 Kaplan-Meier overall survival curves by ALDHI expression. Five-year overall survival for ALDHIAI-positive and ALDHIAI-negative patients was 77.9\% and 62.2\%, respectively $(P=0.002)$.

Abbreviation: ALDHIAI, aldehyde dehydrogenase IAI.

poor survival, ${ }^{26}$ and Chang et al demonstrated that ALDH1 expression correlated with a favorable prognosis in ovarian cancer, ${ }^{27}$ being in line with our study results. It seems possible that one CSC marker from one organ or specific histology is not necessarily useful for identifying CSCs from other organs or histology. In lung ADC, ALDH1 may not be purely a CSC marker but the prognostic marker playing some pivotal role in biologic tumor behavior.

ALDH1A1-positive ADCs demonstrated a significant correlation with less poorly differentiated ADCs, and the frequency of ALDH1A1-positive tumors in papillary predominant ADCs was higher than in solid predominant ADCs.

Table 2 Multivariate analysis of overall survival

\begin{tabular}{|c|c|c|c|}
\hline Variable & Hazard ratio & $95 \% \mathrm{Cl}$ & $P$-value \\
\hline \multicolumn{4}{|l|}{ Tumor size } \\
\hline$\leq 3.0 \mathrm{~cm}$ & 1 & $1.017-3.546$ & 0.044 \\
\hline$>3.0 \mathrm{~cm}$ & 1.899 & & \\
\hline \multicolumn{4}{|l|}{ Lymph node metastasis } \\
\hline Absent & 1 & $1.354-5.392$ & 0.005 \\
\hline Present & 2.702 & & \\
\hline \multicolumn{4}{|l|}{ Vascular invasion } \\
\hline Absent & 1 & $0.897-3.868$ & 0.095 \\
\hline Present & 1.863 & & \\
\hline \multicolumn{4}{|l|}{ Pleural invasion } \\
\hline Absent & I & $0.873-3.831$ & 0.110 \\
\hline Present & 1.829 & & \\
\hline \multicolumn{4}{|l|}{ ALDHIAI expression } \\
\hline$<5 \%$ positive cells & 3.218 & $1.674-6.188$ & $<0.001$ \\
\hline$\geq 5 \%$ positive cells & 1 & & \\
\hline
\end{tabular}

Abbreviations: ALDHIAI, aldehyde dehydrogenase IAI; Cl, confidence interval.
These results suggest that ALDH1A1 may play some role in essential morphogenic functions in lung ADC, and ALDH1A1-positive tumors may indicate lower biological aggressiveness.

Aldo-keto reductase (AKR) enzymes comprise a functionally diverse gene family. ${ }^{28}$ In humans, four AKR1C isoforms have been identified. Of these, $\mathrm{AK} 1 \mathrm{C} 1$ and $\mathrm{AK} 1 \mathrm{C} 3$ are known to be cytosolic oxidoreductases that are involved in reduction of progesterone to the inactive form, 20-alpha hydroxyprogesterone, and the metabolism of steroids and prostaglandins with multispecificity, respectively. ${ }^{29-31}$ Although neither CSC-related immunoreactivity marker had prognostic significance, predominantly solid ADCs had significantly higher expression of AK1C1 when compared with acinar or papillary predominant ADCs.

The prognostic value of the IASLC/ATS/ERS classification of lung $\mathrm{ADC}$ has been validated in several retrospective studies. ${ }^{3,5-7}$ Yoshizawa et al recently reported a significant correlation between EGFR mutations and adenocarcinoma in situ/minimally invasive adenocarcinoma/lepidic/papillary subtypes, and KRAS mutation and mucinous subtypes. ${ }^{6}$ Kadota et al demonstrated that immunoreactions of thyroid transcription factor-1 differ depending on the predominant structural subtype. ${ }^{32}$ In the current study, the histologic subtype appeared to be correlated with specific CSC-related marker expression. The novel classification of lung ADC has important implications, not just for predicting patient prognosis, but also for genetic alterations and molecular biology, and 
Table 3 Correlation between ALDHIAI expression and clinicopathologic characteristics

\begin{tabular}{|c|c|c|c|}
\hline \multirow[t]{2}{*}{ Variable } & \multicolumn{2}{|c|}{ ALDHIAI expression } & \multirow[t]{2}{*}{$P$-value } \\
\hline & $\begin{array}{l}<5 \% \text { positive } \\
\text { cells }\end{array}$ & $\begin{array}{l}\geq 5 \% \text { positive } \\
\text { cells }\end{array}$ & \\
\hline Overall & 35 & 68 & \\
\hline \multicolumn{4}{|c|}{ Age (years, median 65) } \\
\hline$<65$ & 18 & 32 & \\
\hline$\geq 65$ & 17 & 36 & 0.674 \\
\hline \multicolumn{4}{|l|}{ Gender } \\
\hline Male & 18 & 39 & \\
\hline Female & 17 & 29 & 0.567 \\
\hline \multicolumn{4}{|l|}{ Smoking status } \\
\hline Ever smoker & 20 & 39 & \\
\hline Never smoker & 15 & 29 & 0.984 \\
\hline \multicolumn{4}{|l|}{ p Stage } \\
\hline 1 & 24 & 54 & \\
\hline$\|$ & 3 & 9 & (I versus II-IV) \\
\hline III & 7 & 4 & \\
\hline IV & 1 & I & 0.224 \\
\hline \multicolumn{4}{|l|}{ Tumor size } \\
\hline$\leq 3.0 \mathrm{~cm}$ & 21 & 40 & \\
\hline$>3.0 \mathrm{~cm}$ & 14 & 28 & 0.908 \\
\hline \multicolumn{4}{|c|}{ Lymph node metastasis } \\
\hline Absent & 25 & 57 & \\
\hline Present & 10 & II & 0.139 \\
\hline \multicolumn{4}{|l|}{ Differentiation } \\
\hline $\begin{array}{l}\text { Well or } \\
\text { moderate }\end{array}$ & 19 & 53 & \\
\hline Poor & 16 & 15 & 0.013 \\
\hline \multicolumn{4}{|c|}{ IASLC/ATS/ERS classification } \\
\hline AIS & I & 2 & \\
\hline MIA & 0 & 6 & \\
\hline Lepidic & 4 & 4 & \\
\hline Papillary & 10 & 29 & \\
\hline Acinar & 2 & 8 & (AIS-MIA versus \\
\hline Micropapillary & 2 & 3 & invasive ADC) \\
\hline Solid & 15 & 12 & 0.129 \\
\hline \multicolumn{4}{|l|}{ Vascular invasion } \\
\hline Absent & 12 & 31 & \\
\hline Present & 23 & 33 & 0.174 \\
\hline \multicolumn{4}{|l|}{ Pleural invasion } \\
\hline Absent & 28 & 54 & \\
\hline Present & 7 & 14 & 0.944 \\
\hline \multicolumn{4}{|c|}{ Adjuvant chemotherapy } \\
\hline With & 15 & 25 & \\
\hline Without & 20 & 43 & 0.548 \\
\hline
\end{tabular}

Abbreviations: ADC, adenocarcinoma; AIS, adenocarcinoma in situ; MIA, minimally invasive adenocarcinoma; IASLC, International Association for the Study of Lung Cancer; ATS, American Thoracic Society; ERS, European Respiratory Society; ALDHIAI, aldehyde dehydrogenase IAI.

plays a pivotal role as a common language between oncologists/pulmonologists, pathologists, radiologists, molecular biologists, and thoracic surgeons.

In conclusion, although this study is limited because the number of patients was relatively small, the expression of ALDH1A1 is an independent predictor of overall survival.
Moreover, the frequency of ALDH1A1-positive ADCs that were papillary predominant was higher than for solid predominant, and $\mathrm{AK} 1 \mathrm{C} 1$ expression was found to be significantly lower in papillary predominant ADCs than in noninvasive or solid predominant ADCs, suggesting that the comprehensive histologic subtyping approach in the IASLC/ ATS/ERS classification provides new molecular biology insights regarding CSC theory.

\section{Acknowledgments}

The authors are indebted to Professor James M Vardaman of Waseda University and Professor J Patrick Barron, Chairman of the Department of International Medical Communications of Tokyo Medical University, for their editorial review of the English manuscript. This study was supported by grants from the Japanese Ministry of Education, Culture, Sports, Science and Technology (24592104), the Japanese Ministry of Health, Labour and Welfare (22101601), and the Tokyo Medical University of 2012.

\section{Disclosure}

All authors report they have no conflicts of interest associated with this study.

\section{References}

1. Jemal A, Siegel R, Xu J, et al. Cancer statistics, 2010. CA Cancer J Clin. 2010;60:277-300.

2. Travis WD, Brambilla E, Noguchi M, et al. International Association for the Study of Lung Cancer/American Thoracic Society/European Respiratory Society international multidisciplinary classification of lung adenocarcinoma. J Thorac Oncol. 2011;6:244-285.

3. Warth A, Muley T, Meister M, et al. The novel histologic International Association for the Study of Lung Cancer/American Thoracic Society/European Respiratory Society classification system of lung adenocarcinoma is a stage-independent predictor of survival. $J$ Clin Oncol. 2012;30:1438-1446.

4. Xu L, Tavora F, Battafarano R, et al. Adenocarcinomas with prominent lepidic spread: retrospective review applying new classification of the American Thoracic Society. Am J Surg Pathol. 2012;36:273-282.

5. Yoshizawa A, Motoi N, Riely GJ, et al. Impact of proposed IASLC/ATS/ ERS classification of lung adenocarcinoma: prognostic subgroups and implications for further revision of staging based on analysis of 514 stage I cases. Mod Pathol. 2011;24:653-664.

6. Yoshizawa A, Sumiyoshi S, Sonobe M, et al. Validation of the IASLC/ ATS/ERS lung adenocarcinoma classification for prognosis and association with EGFR and KRAS gene mutations: analysis of 440 Japanese patients. J Thorac Oncol. 2013;8:52-61.

7. Russell PA, Wainer Z, Wright GM, et al. Does lung adenocarcinoma subtype predict patient survival? A clinicopathologic study based on the new International Association for the Study of Lung Cancer/ American Thoracic Society/European Respiratory Society international multidisciplinary lung adenocarcinoma classification. J Thorac Oncol. 2011;6:1496-1504.

8. Reya T, Morrison SJ, Clarke MF, et al. Stem cells, cancer, and cancer stem cells. Nature. 2001;414:105-111.

9. Cai J, Cheng A, Luo Y, et al. Membrane properties of rat embryonic multipotent neural stem cells. J Neurochem. 2004;88:212-226. 
10. Ginestier C, Hur MH, Charafe-Jauffret E, et al. ALDH1 is a marker of normal and malignant human mammary stem cells and a predictor of poor clinical outcome. Cell Stem Cell. 2007;1:555-567.

11. Huang EH, Hynes MJ, Zhang T, et al. Aldehyde dehydrogenase 1 is a marker for normal and malignant human colonic stem cells (SC) and tracks SC overpopulation during colon tumorigenesis. Cancer Res. 2009;69:3382-3389.

12. Jiang F, Qiu Q, Khanna A, et al. Aldehyde dehydrogenase 1 is a tumor stem cell-associated marker in lung cancer. Mol Cancer Res. 2009; 7:330-338.

13. Dozmorov MG, Azzarello JT, Wren JD, et al. Elevated AKR1C3 expression promotes prostate cancer cell survival and prostate cellmediated endothelial cell tube formation: implications for prostate cancer progression. BMC Cancer. 2010;10:672.

14. Seo DC, Sung JM, Cho HJ, et al. Gene expression profiling of cancer stem cell in human lung adenocarcinoma A549 cells. Mol Cancer. 2007;6:75.

15. Li X, Wan L, Geng J, et al. Aldehyde dehydrogenase $1 \mathrm{~A} 1$ possesses stem-like properties and predicts lung cancer patient outcome. JThorac Oncol. 2012;7:1235-1245.

16. Patel M, Lu L, Zander DS, et al. ALDH1A1 and ALDH3A1 expression in lung cancers: correlation with histologic type and potential precursors. Lung Cancer. 2008;59:340-349.

17. International Union Against Cancer. TNM Classification of Malignant Tumours. 7th ed. Oxford, UK: Wiley-Blackwell; 2009.

18. Hilton J. Role of aldehyde dehydrogenase in cyclophosphamideresistant L1210 leukemia. Cancer Res. 1984;44:5156-5160.

19. Yoshida A, Rzhetsky A, Hsu LC, et al. Human aldehyde dehydrogenase gene family. Eur J Biochem. 1998;251:549-557.

20. Tanei T, Morimoto K, Shimazu K, et al. Association of breast cancer stem cells identified by aldehyde dehydrogenase 1 expression with resistance to sequential Paclitaxel and epirubicin-based chemotherapy for breast cancers. Clin Cancer Res. 2009;15:4234-4241.

21. Lindahl R. Aldehyde dehydrogenases and their role in carcinogenesis. Crit Rev Biochem Mol Biol. 1992;27:283-335.
22. Storms RW, Trujillo AP, Springer JB, et al. Isolation of primitive human hematopoietic progenitors on the basis of aldehyde dehydrogenase activity. Proc Natl Acad Sci U S A. 1999;96:9118-9123.

23. Kastan MB, Schlaffer E, Russo JE, et al. Direct demonstration of elevated aldehyde dehydrogenase in human hematopoietic progenitor cells. Blood. 1990;75:1947-1950.

24. Hess DA, Meyerrose TE, Wirthlin L, et al. Functional characterization of highly purified human hematopoietic repopulating cells isolated according to aldehyde dehydrogenase activity. Blood. 2004;104: $1648-1655$.

25. Armstrong L, Stojkovic M, Dimmick I, et al. Phenotypic characterization of murine primitive hematopoietic progenitor cells isolated on basis of aldehyde dehydrogenase activity. Stem Cells. 2004;22:1142-1151.

26. Kahlert C, Bergmann F, Beck J, et al. Low expression of aldehyde dehydrogenase 1A1 (ALDH1A1) is a prognostic marker for poor survival in pancreatic cancer. BMC Cancer. 2011;11:275.

27. Chang B, Liu G, Xue F, et al. ALDH1 expression correlates with favorable prognosis in ovarian cancers. Mod Pathol. 2009;22:817-823.

28. Jez JM, Flynn TG, Penning TM. A new nomenclature for the aldo-keto reductase superfamily. Biochem Pharmacol. 1997;54:639-647.

29. Hara A, Matsuura K, Tamada Y, et al. Relationship of human liver dihydrodiol dehydrogenases to hepatic bile-acid-binding protein and an oxidoreductase of human colon cells. Biochem J. 1996;313(Pt 2): 373-376.

30. Lin HK, Jez JM, Schlegel BP, et al. Expression and characterization of recombinant type 23 alpha-hydroxysteroid dehydrogenase (HSD) from human prostate: demonstration of bifunctional 3 alpha/17 beta-HSD activity and cellular distribution. Mol Endocrinol. 1997;11:1971-1984.

31. Khanna M, Qin KN, Wang RW, et al. Substrate specificity, gene structure, and tissue-specific distribution of multiple human 3 alpha-hydroxysteroid dehydrogenases. J Biol Chem. 1995;270:20162-20168.

32. Kadota K, Nitadori J, Sarkaria IS, et al. Thyroid transcription factor-1 expression is an independent predictor of recurrence and correlates with the IASLC/ATS/ERS histologic classification in patients with stage I lung adenocarcinoma. Cancer. 2013;119:931-938.
OncoTargets and Therapy

\section{Publish your work in this journal}

OncoTargets and Therapy is an international, peer-reviewed, open access journal focusing on the pathological basis of all cancers, potential targets for therapy and treatment protocols employed to improve the management of cancer patients. The journal also focuses on the impact of management programs and new therapeutic agents and protocols on

\section{Dovepress}

patient perspectives such as quality of life, adherence and satisfaction The manuscript management system is completely online and includes a very quick and fair peer-review system, which is all easy to use. Visit http://www.dovepress.com/testimonials.php to read real quotes from published authors. 